\title{
Immunological characteristics of a 13-months-old baby with cognitive impairment and mutation in
}

\section{the region of chr9q22.33q32: A case report}

\section{Weitao Zhou ${ }^{1,5}$, Xiaokang Dai ${ }^{2,5}$, Shiqin Nie ${ }^{3}$, Peidong Yan $^{4}$, Mingwu Chen ${ }^{1}$, Dongyao Wang ${ }^{3 *}$}

${ }^{1}$ Department of Pediatrics, The First Affiliated Hospital of the University of Science and Technology of China, Hefei, 230001, China.

${ }^{2}$ Department of Emergency, The First Affiliated Hospital of Anhui Medical University, Hefei, Anhui 230027, China.

${ }^{3}$ Department of Hematology, the First Affiliated Hospital of USTC, Division of Life Sciences and Medicine, University of Science and Technology of China, Hefei, Anhui, 230001, China.

${ }^{4}$ Institute of Immunology, Division of Life Sciences and Medicine, University of Science and Technology of China, Hefei, Anhui, 230001, China. ${ }^{5}$ These authors contributed equally.

*Corresponding Author: Dongyao Wang, Department of Hematology, the First Affiliated Hospital of USTC, Division of Life Sciences and Medicine, University of Science and Technology of China, Hefei, Anhui, 230001, China.

Received date: 04 January 2022; Accepted date: 12 January 2022; Published date: 19 January 2022

Citation: Zhou W, Dai X, Nie S, Yan P, Chen M, et al. (2022) Immunological characteristics of a 13-months-old baby with cognitive impairment and mutation in the region of chr9q22.33q32: A case report J Med Case Rep Case Series 3(01):

https://doi.org/10.38207/JMCRCS/2022/JAN030101

Copyright: (C) 2022 Dongyao Wang. This is an open-access article distributed under the terms of the Creative Commons Attribution License, which permits unrestricted use, distribution, and reproduction in any medium, provided the original author and source are credited.

\begin{abstract}
Background: Mutations in the genes are responsible for multiple hereditary human diseases, including cognitive impairment. However, the mechanism and the concomitant immunological characteristics are rarely reported in babies.
\end{abstract}

Case presentation: In this study, a 13-months-old baby was screened, and a series of experiments including chromosome microarray analysis (CMA) and flow cytometry were conducted to investigate the characteristic of the patient. Through CMA, we found the deletion mutation in the region of chr9q22.33q32, which includes the gene encoding the bile acid-CoA: amino acid N-acyltransferase (BAAT). What's more, we found the baby had hyperbilirubinemia. In addition, the percentage of CD24 CD38 high regulatory B (Breg) cells was high, while the percentage of Natural killer (NK) cells was low. Moreover, in the parents, there was not any abnormal change of copy number in the region of chr9q22.33q32; furthermore, the percentage of Breg cells and NK cells was normal.

Conclusions: These findings revealed a possible cause of cognitive impairment, which involved genetic mutations and a high proportion of Breg cells. Importantly, CD24, the identified marker of Breg cells might be targetable for the disease.

Keywords: Breg cells, NK cells, CD24, case report, BAAT.

\section{Introduction}

\section{Background}

Cognitive impairment may occur at the very earliest stages and would be further exacerbated by metabolic syndrome [1]. The pathophysiology of cognitive impairment is multifactorial, and the duration of bile acid synthesis disorder may have an impact on the type and severity of cognitive impairment [2]. Several promising therapies have been performed in pre-clinical studies but remain to be validated in clinical trials.

Mutations in the genes encoding the bile acid-CoA: amino acid Nacyltransferase (BAAT) are responsible for multiple hereditary human diseases [3]. The protein encoded by this gene is a liver enzyme that would catalyze the transfer of bile acids from the acylCoA thioester to either taurine or glycine. Defects in this gene are a cause of hyperbilirubinemia, which now is thought to be associated with cognitive impairment [2].
The interplay between the immune system and cognitive impairment is complex. Natural killer (NK) cells originate from hematopoietic stem cells (HSCs), and the NK cell function is finely tuned by activating and inhibitory receptors, allowing NK cells to discriminate between normal and aberrant cells [4]. What's more, NK cells would contribute to Alzheimer's Disease (AD), and targeted NK cells might be novel strategies to combat $\mathrm{AD}[5]$. $\mathrm{CD} 24^{+} \mathrm{CD} 38^{\text {high }}$ regulatory $\mathrm{B}$ (Breg) cells are part of the adaptive immune response, and recent data suggested that they may contribute to a healthy pregnancy by their regulatory/suppressive function [6]. What's more, Breg cells could inhibit the differentiation of Th1 and Th17 cells and suppress effector $\mathrm{CD}^{+}$and $\mathrm{CD}^{+} \mathrm{T}$ cells via the release of $\mathrm{IL}-10$ [7]. In addition, patients with benign multiple sclerosis showed cognitive impairment and increased Breg cells, which may play a role in it [8]. CD24 is a small, glycophosphatidylinositol-anchored cell surface protein, and is 
mostly investigated in inflammation, cancer, and autoimmune diseases [9]. CD24 has also been identified as a marker of Breg cells [7]. Furthermore, CD24 plays a significant role in glioma tumorigenesis. Overexpression of CD24 could stimulate glioma cell migration and invasion. Likewise, using anti-CD24 neutralizing monoclonal antibodies would attenuate glioma tumor growth [10]. Moreover, Keren Nitzan et al. demonstrated that $\mathrm{CD} 24^{-/-}$mice exhibited better cognitive performance compared with WT mice, with

\section{Methods}

Patient data were collected via retrospective chart review, which included clinical characteristics; chromosome microarray analysis (CMA), and flow cytometry [11]. Detailed methods are available in the Supplementary material. The case report was conducted in

\section{Case presentation}

The baby is a boy, born at $40^{+5}$ weeks' gestational age, the first child of non-consanguineous parents. The baby was delivered by Caesarean section with $\mathrm{II}^{\circ}$ polluted amniotic fluid. The Apgar score was 10 points in 1 minute and 10 points in 5 minutes. On day 2, the boy was diagnosed with neonatal pneumonia and neonatal hyperbilirubinemia. The value of Creatine Kinase-MB was $105 \mathrm{U} / \mathrm{L}$ at 1 year old. The baby lifted his head at 4-month old and rolled over at 8-month old; Next, he could stand at 10-month old. Now, he could not crawl or say, mama. The characteristics of the 13-months-old boy
Journal of Medical Case Reports and Case Series 6 ISSN: 2692-9880 no effect on depression-like behavior [9]. Therefore, if the patient with cognitive impairment showed an abnormal percentage of Breg cells, and if CD24 could be targetable for the disease remain to be explored.

Here, we examined the characteristics of the baby with cognitive impairment and demonstrated the abnormal proportion of Breg cells in the blood, to ascertain whether abnormal Breg cells are related to cognitive impairment. accordance with the Declaration of Helsinki. The case report was approved by the institutional review board of the First Affiliated Hospital of the University of Science and Technology of China.

are shown in (Table S1). The boy was diagnosed with hyperbilirubinemia with cognitive impairment in the First Affiliated Hospital of the University of Science and Technology of China. Through CMA, we found the deletion mutation in the region of chr9q22.33q32 (99173949_112961198), which included the gene encoding BAAT, the defects in which are a cause of hyperbilirubinemia. Importantly, altered bile acid profile could associate with cognitive impairment [2]. In the parents, there was not any abnormal change in the region of chr9q22.33q32.

Table S1: Baseline characteristics of the patient

\begin{tabular}{ll}
\hline Characteristic & Value \\
\hline Gender $(\mathrm{M} / \mathrm{F})$ & $\mathrm{M}$ \\
Age, months & 13.0 \\
Cognitive impairment $(\mathrm{Y} / \mathrm{N})$ & $\mathrm{Y}$ \\
White blood cell count, $\times 10^{9} / \mathrm{L}$ & 6.38 \\
Red blood cell count, $\times 10^{12} / \mathrm{L}$ & 4.15 \\
Platelet count, $\times 10^{9} / \mathrm{L}$ & 240 \\
Lymphocyte count, $\times 10^{9} / \mathrm{L}$ & 2.37 \\
Neutrophil count, $\times 10^{9} / \mathrm{L}$ & 3.10 \\
CRP $(\mathrm{mg} / \mathrm{L})$ & 8.25 \\
TBil $(\mu \mathrm{mol} / \mathrm{L})$, & 175.9 \\
Direct bilirubin $(\mu \mathrm{mol} / \mathrm{L})$ & 3.15 \\
Indirect bilirubin $(\mu \mathrm{mol} / \mathrm{L})$ & 175.25 \\
TP $(\mathrm{g} / \mathrm{L})$ & 58.78 \\
Albumin $(\mathrm{g} / \mathrm{L})$ & 34.54 \\
ALT $(\mathrm{u} / \mathrm{L})$ & 40.62 \\
Urea nitrogen $(\mathrm{mmol} / \mathrm{L})$ & 4.09 \\
Creatinine $(\mu \mathrm{mol} / \mathrm{L})$ & 68.34 \\
Hemoglobin $(\mathrm{g} / \mathrm{L})$ & 145
\end{tabular}

Y/N, Yes/No; M, Male; CRP, C-reactive protein; TBil, total bilirubin; TP, total protein; ALT, alanine transaminase. 
Thereafter, to investigate the immunological characteristics and the possible mechanism underlying the cognitive impairment, we isolated mononuclear cells from the peripheral blood and systematically analyzed the immunological characteristics. We found the percentage of $\mathrm{CD}^{2} 6^{+} \mathrm{CD}^{-} \mathrm{NK}$ cells were quite low (only about $3 \%$ ), while the percentage of $\mathrm{CD} 24^{+} \mathrm{CD} 38^{\text {high }}$ Breg cells was high (about $30 \%$ ) in the patient (Figure 1A) [6,7,12]. However, the percentage of Breg cells and NK cells in the parents was normal. Human NK cells can be classified into two main classic subsets dependent on CD56 and CD16: $\mathrm{CD}^{2} 6^{\text {bright }} \mathrm{CD} 16^{-}$and $\mathrm{CD} 56^{\mathrm{dim}} \mathrm{CD} 16^{+} \mathrm{NK}$ cells [13]. The former is considered an efficient cytokine producer. The proportion of these cells was nearly $69 \%$ in the patient (Figure 1B). The NK cell's function is finely tuned by activating and inhibitory receptors,
Journal of Medical Case Reports and Case Series ISSN: 2692-9880 allowing NK cells to discriminate between normal and aberrant cells [4], thus we analyzed the receptors of NK cells, and we did not find the significant change of NKp30 and NKG2D expression (Figure 1B). What's more, we found the expression of KIR3DL1 was low in the patient. In addition, the proportion of $\mathrm{CD} 14^{+} \mathrm{CD} 16^{+}$inflammatory monocytes seemed normal in the patient, while high in the mother (Figure 1B). Furthermore, we found the expressions of inhibitory molecules such as NKG2A and PD-1 in $\mathrm{CD}^{+} \mathrm{T}$ cells, as well as the proportion of $\mathrm{NKG}_{2} \mathrm{~A}^{+} \mathrm{KLRG} 1^{+} \mathrm{NK}$ cells, were low in the patient, but high in the mother (Figure 1C). Collectively, we demonstrated that the proportion of Breg cells was extraordinarily elevated in the patient. Although the proportion of NK cells decreased, the expression of the inhibitory molecular was not increased.

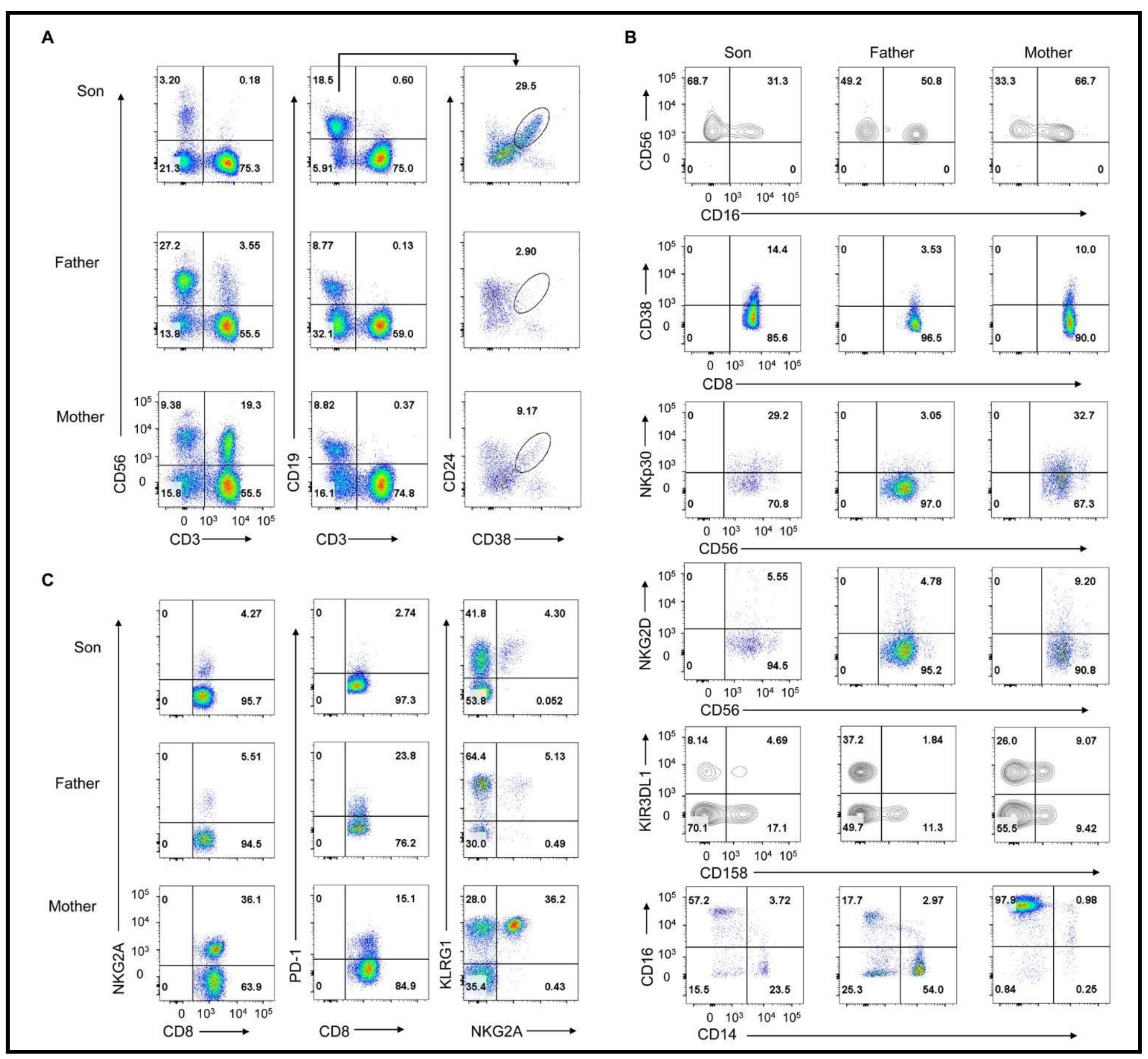

Figure 1: Increased Breg cells and decreased NK cells in the patient.

Mononuclear cells were derived from the PB (peripheral blood) of the patient and his parents.

(A) Density plots of $\mathrm{CD}^{2} 6^{+} \mathrm{CD} 3^{-} \mathrm{NK}$ cells and $\mathrm{CD} 56^{-} \mathrm{CD}^{+} \mathrm{T}$ cells (left), $\mathrm{CD} 19^{+} \mathrm{CD} 3^{-} \mathrm{B}$ cells (middle), and CD24 ${ }^{+} \mathrm{CD} 38$ high Breg cells (right) in gated $\mathrm{CD} 45^{+}$cells from PBMC of the patient (above), the father (middle), and the mother (below).

(B) Density plots of CD56 bright NK cells, CD $38^{+} \mathrm{CD}^{+} \mathrm{T}$ cells, NKp30 $0^{+} \mathrm{NK}$ cells, NKG2D $\mathrm{NK}^{+}$cells, CD158 ${ }^{+} \mathrm{NK}$ cells, and CD14 ${ }^{+} \mathrm{CD} 16^{+}$ monocytes in gated $\mathrm{CD} 45^{+}$cells from $\mathrm{PBMC}$ of the patient (left), the father (middle), and the mother (right).

(C) Density plots of $\mathrm{NKG}_{2} \mathrm{~A}^{+} \mathrm{CD} 8^{+} \mathrm{T}$ cells (left), $\mathrm{PD}-1^{+} \mathrm{CD} 8^{+} \mathrm{T}$ cells (middle), and $\mathrm{KLRG} 1^{+} \mathrm{NKG} 2 \mathrm{~A}^{+} \mathrm{NK}$ cells (right) in gated $\mathrm{CD} 45^{+}$cells from PBMC of the patient (above), the father (middle), and the mother (below). 


\section{Discussion and Conclusions}

Over the last decade, the importance of identifying and treating cognitive impairment is getting more and more attention. It is important to get a better understanding of potential moderators contributing to cognitive impairment and find effective treatments. All these data encourage the development of further studies to find effective strategies to prevent and treat cognitive impairment associated with bipolar disorder. These efforts may ultimately lead to an improvement of psychosocial functioning in these patients.

Here, we firstly demonstrated that the 13-months-old baby with the deletion mutation in the region of chr9q22.33q32, which includes the gene encoding the BAAT, was diagnosed with hyperbilirubinemia and showed cognitive impairment. As there is no effective treatment for cognitive impairment, we then tried to find breakthroughs from immunological characteristics. We found the percentage of $\mathrm{CD} 24^{+} \mathrm{CD} 38^{\text {high }}$ Breg cells was high in the patient. However, in the parents there was not any mutation in the region of chr9q22.33q 32 ; furthermore, the percentage of Breg cells was normal.

Given that NK cells would contribute to nervous system disease, including AD [5], next, we analyzed the data and found the NK cells

Abbreviations: CMA: chromosome microarray analysis; Breg: regulatory B; NK: Natural killer; BAAT: bile acid-CoA: amino acid $\mathrm{N}$-acyltransferase

\section{Declarations}

Ethics approval and consent to participate: The case report was conducted in accordance with the Declaration of Helsinki. The case report was approved by the institutional review board of the First Affiliated Hospital of the University of Science and Technology of China. Written informed consent was obtained from the participant.

Consent to publish: A written informed consent was obtained from the father of the child.

Availability of data and materials: The data that support the findings of this study are available from the authors upon reasonable request.

Competing interests: The authors declare that they have no competing interests.

\section{References}

1. Zilliox LA, Chadrasekaran K, Kwan JY, Russell JW (2016) Diabetes and Cognitive Impairment. Current Diabetes Reports. 16(9): 87.

2 MahmoudianDehkordi S, Arnold M, Nho K, Ahmad S, Jia W, et al. (2019) Altered bile acid profile associates with cognitive impairment in Alzheimer's disease-An emerging role for gut microbiome. Alzheimers Dement. 15(1): 76-92.

3. Ding L, Yang L, Wang Z, Huang W (2015) Bile acid nuclear receptor FXR and digestive system diseases. Acta Pharm Sin B. in the patient decreased with the normal expression of inhibitory molecular, such as NKG2A and KIR3DL1. Thus, we considered that the increasing Breg cells might play a more important role in cognitive impairment. CD24 was identified as a marker of Breg cells, and anti-CD24 neutralizing monoclonal antibody had been used to attenuate glioma tumor growth [10]. Therefore, we wonder if CD24 could be targetable for the disease.

However, the present study had three main limitations. Firstly, due to the limited number of peripheral blood samples from the patient, we did not test for more markers, or the function of T cells and NK cells. Secondly, we did not clarify the correlation between Breg cells and the gene BAAT. Thirdly, there were other genes in the region of chr9q22.33q32, such as ZNF462, however, we did not analyze the possible correlation between these genes and the cognitive impairment.

Taken together, this study provides new perspectives on the possible mechanism underlying cognitive impairment, and treatment with antiCD24 monoclonal antibody might be worthy of consideration.

Funding: This work was supported by the China postdoctoral science foundation (2020M671910), the Postdoctoral Foundation of Hefei (2020130), and the Fundamental Research Funds for the Central Universities (WK9110000168) (to DW).

Authorship Contributions: All authors have read and approved the manuscript. WZ and XD designed and performed the experiments, analyzed and interpreted the data. XD helped to analyze andinterpret the data. SN and PY helped to collect samples and information from patients and design the experiments and analyze the data. DW and MC supervised the project, provided crucial ideas, and assisted with data interpretation. DW wrote the manuscript with MC.

Acknowledgments: The authors thank their colleagues at the First Affiliated Hospital of the University of Science and Technology of China for collaboration on the care of the patient.

$5(2): 135-44$

4. Li H, Er Saw P, Song E (2020) Challenges and strategies for nextgeneration bispecific antibody-based antitumor therapeutics. Cellular \& molecular immunology. 17: 451-461.

5. Zhang Y, Fung ITH, Sankar P, Chen X, Robison LS, et al. (2020) Depletion of NK Cells Improves Cognitive Function in the Alzheimer Disease Mouse Model. J Immunol. 205(2): 502-510.

6. Esteve-Solé A, Luo Y, Vlagea A, Deyà-Martínez Á, Yagüe J, et al. (2018) B Regulatory Cells: Players in Pregnancy and Early Life. 
Int J Mol Sci. 19(7): 2099

7. Fu B, Wang D, Shen X, Guo C, Liu Y, et al. (2020) Immunomodulation Induced During Interferon- $\alpha$ Therapy Impairs the Anti-HBV Immune Response Through CD24(+)CD38(hi) B Cells. Front Immunol. 11: 591269.

8. Turkoglu R, Yilmaz V, Ozdemir O, Akbayir E, Benbir G, et al. (2021) Peripheral blood B cell subset ratios and expression levels of B cell-associated genes are altered in benign multiple sclerosis. Mult Scler Relat Disord. 52: 103019.

9. Nitzan K, Toledano R, Shapira S, Arber N, Doron R (2021) Behavioral Characterizing of CD24 Knockout Mouse-Cognitive and Emotional Alternations. J Pers Med. 11(2): 105.

10. Barash U, Spyrou A, Liu P, Vlodavsky E, Zhu C, et al. (2019)
Heparanase promotes glioma progression via enhancing CD24 expression. Int J Cancer. 145(6): 1596-1608.

11. Zheng X, Qian Y, Fu B, Jiao D, Jiang Y, et al. (2019) Mitochondrial fragmentation limits NK cell-based tumor immunosurveillance. Nature immunology. 20(12): 1656-1667.

12. Fang J, Lin L, Lin D, Zhang R, Liu X, et al. (2019) The imbalance between regulatory memory $\mathrm{B}$ cells reveals possible pathogenesis involvement in pediatric immune thrombocytopenia. Hematology. 24(1): 473-479.

13. Forconi CS, Cosgrove CP, Saikumar-Lakshmi P, Nixon CE, Foley J, et al. (2018) Poorly cytotoxic terminally differentiated CD56(neg)CD16(pos) NK cells accumulate in Kenyan children with Burkitt lymphomas. Blood advances. 2(10): 1101-1114. 


\section{Supplementary Materials and Methods}

\section{Flow cytometry}

Mononuclear cells were firstly derived from the bone marrow and the mononuclear cell suspensions were then treated with mouse serum to block the binding to non-specific Fc receptors. Next, to assess the surface and intracellular markers, the cells were stained with anti-human monoclonal antibodies, from BD Biosciences and Bio Legend, in accordance with the manufacturer's instructions. Data were collected using an FCM LSR II flow cytometer (BD Biosciences, USA) and analyzed using FlowJo software (Tree Star, USA).

Table S2: Antibodies used in flow cytometric analysis

\begin{tabular}{|c|c|c|}
\hline Antibody & Brand & Cat. No. \\
\hline $\begin{array}{l}\text { APC-CY7 Mouse } \\
\text { Anti-Human CD3 }\end{array}$ & BD Bioscience & $\begin{array}{lr}\text { Cat\# } & 557832, \\
\text { RRID:AB_396890 }\end{array}$ \\
\hline $\begin{array}{l}\text { FITC Mouse Anti- } \\
\text { Human CD16 }\end{array}$ & BD Bioscience & $\begin{array}{l}\text { Cat\# } 555406 \text {, } \\
\text { RRID:AB_395806 }\end{array}$ \\
\hline $\begin{array}{l}\text { FITC Mouse Anti- } \\
\text { Human CD27 }\end{array}$ & BD Bioscience & $\begin{array}{l}\text { Cat\# } 555440 \text {, } \\
\text { RRID:AB_395833 }\end{array}$ \\
\hline $\begin{array}{l}\text { APC-Cy7 Mouse } \\
\text { Anti-Human CD14 }\end{array}$ & BD Bioscience & Cat\# 557831 \\
\hline $\begin{array}{l}\text { PerCP-CY5.5 } \\
\text { Mouse Anti- } \\
\text { Human CD38 }\end{array}$ & BD Bioscience & $\begin{array}{l}\text { Cat\# } 551400, \\
\text { RRID:AB_394184 }\end{array}$ \\
\hline $\begin{array}{l}\text { FITC Mouse Anti- } \\
\text { Human CD4 }\end{array}$ & BD Pharmingen & $\begin{array}{l}\text { Cat\# } 555346 \text {, } \\
\text { RRID:AB_395751 }\end{array}$ \\
\hline $\begin{array}{l}\text { PE-Cy7 Mouse } \\
\text { Anti-Human CD8 }\end{array}$ & BD Pharmingen & $\begin{array}{l}\text { Cat\# } 557746 \text {, } \\
\text { RRID:AB_396852 }\end{array}$ \\
\hline $\begin{array}{l}\text { PE Mouse Anti- } \\
\text { Human PD-1 }\end{array}$ & BD Bioscience & Cat\#560795, \\
\hline $\begin{array}{l}\text { APC Mouse Anti- } \\
\text { Human HLA-DR }\end{array}$ & BD Bioscience & $\begin{array}{l}\text { Cat\# } 559866 \text {, } \\
\text { RRID:AB_398674 }\end{array}$ \\
\hline $\begin{array}{l}\text { PE Mouse Anti- } \\
\text { Human NKG2D }\end{array}$ & BD Bioscience & Cat\# 557940 \\
\hline $\begin{array}{l}\text { Alexa Fluor® } 647 \\
\text { Mouse Anti- } \\
\text { Human NKP30 }\end{array}$ & BD Bioscience & $\begin{array}{l}\text { Cat\# } 558408 \text {, } \\
\text { RRID:AB_398454 }\end{array}$ \\
\hline $\begin{array}{l}\text { FITC Mouse IgG1, } \\
\kappa\end{array}$ & $\mathrm{BD}$ & $\begin{array}{l}\text { Cat\# } \quad 555748 \text {, } \\
\text { RRID:AB_396090 }\end{array}$ \\
\hline PE Mouse IgG1, $\kappa$ & $\mathrm{BD}$ & $\begin{array}{l}\text { Cat\# } 55749 \text {, } \\
\text { RRID:AB_396091 }\end{array}$ \\
\hline $\begin{array}{l}\text { PerCP-Cy5.5 } \\
\text { Mouse IgG1, א }\end{array}$ & $\mathrm{BD}$ & $\begin{array}{l}\text { Cat\# 552834, } \\
\text { RRID:AB_394484 }\end{array}$ \\
\hline $\begin{array}{ll}\text { PE-Cy7 } & \text { Mouse } \\
\text { IgG } 1, \kappa & \end{array}$ & $\mathrm{BD}$ & $\begin{array}{l}\text { Cat\# } 557872 \text {, } \\
\text { RRID:AB_396914 }\end{array}$ \\
\hline $\begin{array}{l}\text { Alexa Fluor } 647 \\
\text { Mouse IgG1, } \kappa\end{array}$ & $\mathrm{BD}$ & $\begin{array}{l}\text { Cat\# } 557714 \text {, } \\
\text { RRID:AB_396823 }\end{array}$ \\
\hline $\begin{array}{l}\text { APC-Cy7 Mouse } \\
\text { IgG1, } \kappa\end{array}$ & $\mathrm{BD}$ & $\begin{array}{l}\text { Cat\# } 557873 \text {, } \\
\text { RRID:AB_396915 }\end{array}$ \\
\hline $\begin{array}{l}\text { APC-Сy7 } \\
\operatorname{IgG1,\kappa x}\end{array}$ & Biolegend & $\begin{array}{l}\text { Cat\# } 400161, \\
\text { RRID:AB_11125373 }\end{array}$ \\
\hline
\end{tabular}


PE Mouse IgG2a, $\kappa \quad B D$

Cat\#

555574

RRID:AB_395953

PerCP-Cy5.5

Mouse IgG2a, $\kappa$

$\mathrm{BD}$

Cat\# 558020,

PE-Cy7 Mouse

$\operatorname{IgG} 2 b, \kappa$
RRID:AB_396989

Biolegend Cat\# 400325

No., number; Cat., catalog; RRID, Research Resource Identifier. 